\title{
Correction to: A mutation in NOTCH2 gene first associated with Hajdu-Cheney syndrome in a Greek family: diversity in phenotype and response to treatment
}

\author{
Zoe A. Efstathiadou ${ }^{1}{ }^{1} \cdot$ Charilaos Kostoulas $^{2} \cdot$ Stergios A. Polyzos $^{3} \cdot$ Fotini Adamidou $^{1} \cdot$ Ioannis Georgiou $^{2}$. \\ Marina Kita ${ }^{1}$
}

Published online: 6 October 2020

(c) Springer Science+Business Media, LLC, part of Springer Nature 2020

Correction to: Endocrine

https://doi.org/10.1007/s12020-020-02446-7.
Following publication of the original article, the authors reported an error in Fig. 3 which was inadvertently published. The corrected figure 3 is given below.

The original article has been corrected.

Publisher's note Springer Nature remains neutral with regard to jurisdictional claims in published maps and institutional affiliations.

The original article can be found online at https://doi.org/10.1007/ s12020-020-02446-7.

Zoe A. Efstathiadou

zefsta@endo.gr

1 Department of Endocrinology, "Hippokration" General Hospital of Thessaloniki, Thessaloniki, Greece

2 Laboratory of Medical Genetics in Clinical Practice, Faculty of Medicine, University of Ioannina, Ioannina, Greece

3 First Laboratory of Pharmacology, School of Medicine, Aristotle University of Thessaloniki, Thessaloniki, Greece 
Fig. 3 Imaging of the spine in mother (a) and two siblings (son (b), daughter (c))
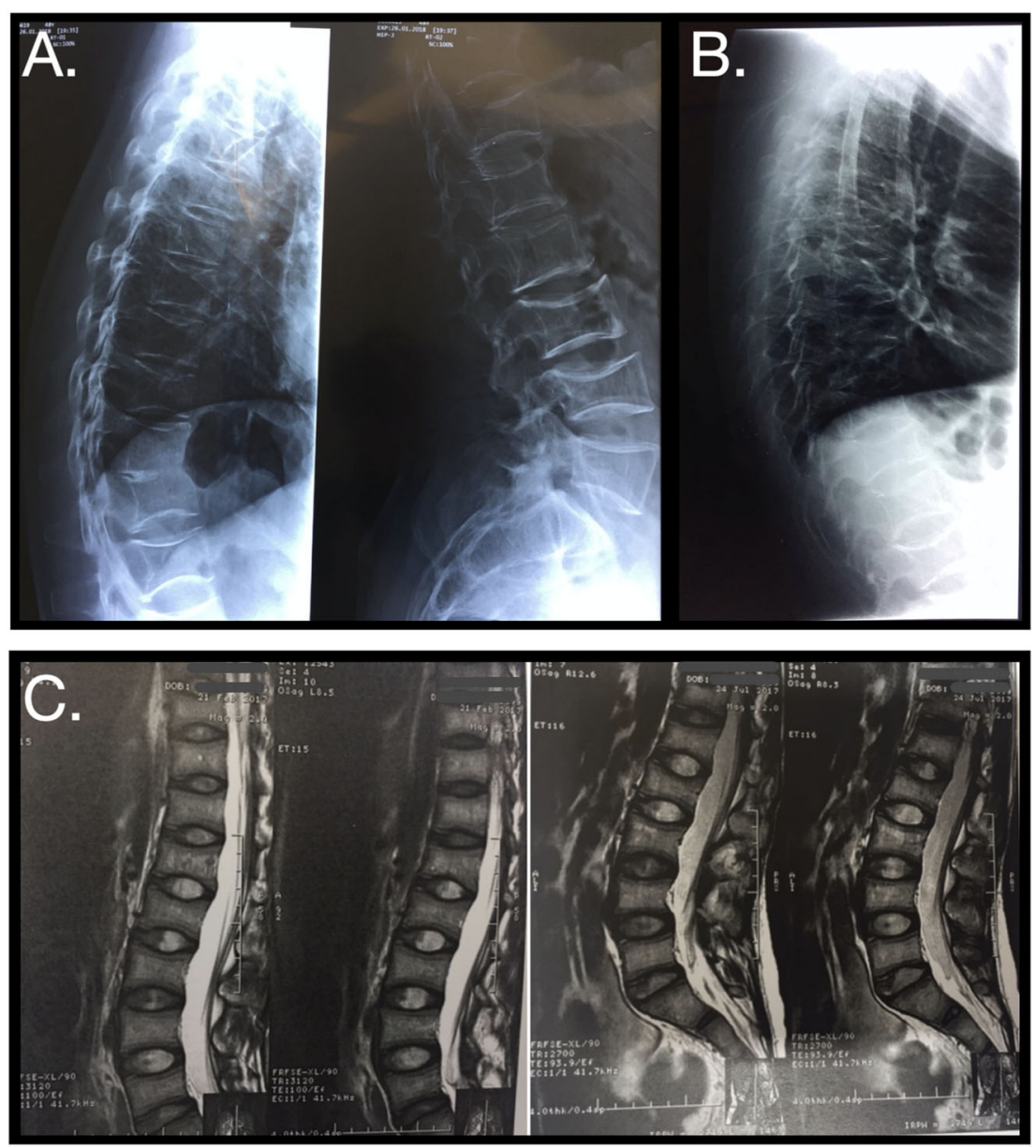